\title{
Clinicians and the economic evaluation of health
}

José G Merino, MD, M Phil. ${ }^{(1)}$

\begin{abstract}
Merino JG.
Clinicians and the economic evaluation of health. Salud Publica Mex 2002;44:153-157. The English version of this paper is available too at: http://www.insp.mx/salud/index.html
\end{abstract}

\begin{abstract}
A bstract
Papers dealing with the economic evaluation of health care have proliferated in the clinical literature. They provide an evidence-based element to help policy makers allocate resources among competing projects. These studies are generally done from a the perspective of a health provider (public or practice) or a public health professional, they do not take into account the special nature of the patient-physician relationship. The value of these studies for a clinician caring for an individual patient is questioned because the perspective used and the values measured represent those of society or a health provider, not those of patients. In addition, since cost-effectiveness analysis fails to take into account important societal ethical beliefs that are relevant to the care of individuals, its application to individual care is limited. Physicians should use these analyses when working as private or public policy makers, not as clinicians. The English version of this paper is available too at: http:// www.insp.mx/salud/index.html
\end{abstract}

Key words: economics medical; cost effectiveness analysis; medical ethics; public health; health policy

\author{
Merino JG. \\ Los clínicos y la evaluación económica de la salud. \\ Salud Publica Mex 2002;44:153-157. \\ El texto completo en inglés de este artículo también \\ está disponible en: http://www.insp.mx/salud/index.html
}

\section{Resumen}

Recientemente han proliferado en la literatura clínica estudios de la evaluación económica de la atención a la salud. Este tipo de análisis permite aplicar los principios de la atención a la salud, basada en la evidencia de decisiones que afectan la distribución de recursos entre proyectos alternativos. El hecho de que estos estudios generalmente se llevan a cabo desde una perspectiva de salud pública o de la de un organismo proveedor de servicios (público o privado), y que no toman en cuenta las características particulares de la relación médico-paciente, hace que su valor para un médico que se ocupa de un paciente individual sea limitado. En este ensayo se cuestiona la utilidad de estos estudios en la práctica clínica cotidiana. Un problema fundamental es que los valores medidos en los análisis económicos son los de la sociedad en su conjunto o los de un proveedor de salud, no los de un paciente específico. Adicionalmente, los estudios de costo-efectividad no toman en cuenta creencias éticas de la sociedad que son relevantes para el cuidado de los individuos. Los resultados de estos estudios son muy importantes para los que determinan las políticas de salud (incluso para los clínicos cuando actúan como administradores de recursos para la salud), pero no en la interacción clínica entre un médico y un paciente. El texto completo en inglés de este artículo también está disponible en: http://www.insp.mx/salud/index.html

Palabras clave: economía médica; análisis de costo-efectividad; ética médica; salud pública; política de salud

This paper was made possible in part by Fisher Family/Heart and Stroke Foundation of 0 ntario Research Fellowship Award \#4528.

(1) Department of N eurology. U niversity of Florida Health Sciences C enter/Jacksonville, Florida, Estados U nidos de América.

Received on: January 11, 2001 - Accepted on: 0 ctober 10, 2001

Address reprint requests to: Dr José G Merino. D epartment of N eurology, University of Florida Health Sciences Center-Jacksonville, 580 W est Eight Street, Plaza I, gth floor, Jacksonville, FL 32209-6511, E.U.A. E-mail: jose.merino@ jax.ufl.edu 
$A s$ a practicing physician I have been intrigued by $A$ the proliferation of papers dealing with the economic evaluation of health care in clinical journals. This proliferation reflects a growing awareness among physicians, health care policy makers and the general public that the resources available for health care are limited and that for every dollar spent in one project, health related or otherwise, other programs have to be foregone (there is an opportunity cost attached to every allocation decision). Recognizing this quandary the question that arises is: should a physician alter her pattern of clinical practice based on the results of published economic evaluations of health care? Should a physician working in the clinic apply to individual patients the findings of an instrument designed to help policy makers (physicians and otherwise) set priorities for the allocation of resources among competing projects? If this is not the case, what is the benefit of having these studies published in general clinical journals? At a more fundamental level, is there a role for "bed-side" economics? ${ }^{1}$ Should individual physicians be providing care based on considerations other than the best interest of the patient, such as societal good? To address these questions this paper will examine what cost-effectiveness analysis is and what it means, some of the assumptions that go into an economic evaluation, and ways that these can be used by physicians involved with decision making at different levels, from micro to macro.

\section{Economic evaluation of health care}

Cost-effectiveness analysis (CEA) is a powerful analytical technique that measures the health benefit that is obtained from a given expenditure. By comparing outcomes in relation to costs, CEA helps decisionmakers determine which health interventions would optimize health outcomes given a limited budget. All forms of economic evaluations consider costs in a similar manner, however they differ on how outcomes are measured. In its classical form, CEA measures outcomes in terms of natural units, such as $\mathrm{mg} / \mathrm{dl}$ of cholesterol or years of life gained. In a variation of this approach, traditionally called cost-utility analysis (CUA) but increasingly referred to as CEA in the literature (and in this paper), the effectiveness of health interventions is measured in common units of health related value, such as the quality adjusted life year (QALY). These measures are based on preferences expressed by groups of patients or the public through the assignment of subjective utility values to specific health states. ${ }^{2}$ Several techniques, such as the standard gamble and the time trade off models, are used to obtain these utility values. ${ }^{3}$ Current recommendations emphasize the use of CUA approach when performing cost-outcome studies, ${ }^{4}$ and the most commonly used outcome measure in this type of analysis is the QALY. ${ }^{3}$ QALYs incorporate three factors: the size of quality improvement that a given treatment or diagnostic intervention produces, the duration of the health improvement, and the number of persons that can be expected to benefit from the intervention. ${ }^{2}$

Textbooks $^{3}$ and guidelines ${ }^{4}$ to help the clinician evaluate the technical and statistical quality of a CEA have been published recently, they will likely lead to an increase in the number of cost-effectiveness studies published in the clinical literature. To assess the relationship between CEA studies and clinical decision making it is worthwhile to explores some components and underlying assumptions that go into CEA studies: the concept of worth and who decides how much something is worth, the importance of the perspective used in the cost-outcome analysis, the different perspectives of those involved in health related decision making, and the issue of values for different decision makers.

\section{Assumptions of cost-effectiveness analysis and their relevance to the clinic}

What is the meaning of "cost-effective"? Different uses of the term have led to great confusion in the literature. In an attempt to clarify the issue, Doubliet ${ }^{5}$ has identified four ways in which the term is currently used: a) as a synonym for cost savings; b) as a synonym for clinical effectiveness, c) when referring to cost savings that lead to an equal or better health outcome, and d) when an intervention leads to the production of an additional benefit that is felt to be worth the extra cost. He agrees with the last two uses of the term. Allan Detsky ${ }^{6}$ favors the last definition, and he refers to such an intervention as "economically attractive" because the term "implies a cost effectiveness ratio below the threshold that society is willing to bear for health gains." ${ }^{\prime 6}$

The concept of "worth the extra cost" is key to understanding the role that economic evaluations play in the decision making process. A technically adequate CEA informs the policy maker of how many dollars have to be spent to obtain a given outcome (measured in QALYs) for the intervention being evaluated. ACEA study does not determine whether the benefits are worth the cost or not. In that sense, it is a descriptive and not a prescriptive instrument. The decision of how much each QALY is worth implies a difficult value judgement. Since society will ultimately pay for the 
benefits (through taxation or payment of insurance premiums and "out of pocket" expenses), society must make this judgement through political means. Strategies to aid in determining what is a "good value for the money" have been established recently, but they remain controversial. ${ }^{8}$ Since the value placed on a given outcome must be determined by society, it follows that the decision of how much should be spent to obtain that outcome cannot be determined by a physician interacting with a particular patient.

A related issue is the question of the perspective that is used in CEA. The point of view used in the CEA will determine which costs and benefits are evaluated. Recent recommendations ${ }^{4}$ stress the value of performing economic evaluations from a societal perspective because the goal of using economic evaluations to set health policy should be to maximize the health of the population, given a fixed budget. Choosing the societal approach implies that the costs will be borne, and the benefits enjoyed, by society in general, ${ }^{9}$ assuming that through a redistributive process those who benefit from any intervention may potentially compensate those who lose. The application of the intervention is thus a public policy issue. ACEA done from the point of view of society has limited applicability to an individual case, since the risk to each individual is greater than the risk perceived from a population perspective ${ }^{9}$ because each person is unlikely to bear the average burden and receive the average benefit. ${ }^{10}$ Economic evaluations of health are analytical tools that help assess the feasibility of various competing health interventions at the group level. Clinicians are primarily concerned with outcomes at the individual level.

When dealing with individual patients, physicians are more concerned with clinical rather than cost effectiveness. ${ }^{11}$ Physicians give more weight to the personal concerns of patients when considering them as individuals and more weight to general criteria of effectiveness when considering them as a group ${ }^{12}$ Patient centered care should reflect the preference of patients, not those of society or other groups (government, other health care providers).

An inescapable question that arises when measuring values is, whose values should be measured? Should the values of patients affected with a disease be used? After all, they have first hand experience of the quality of life associated with that particular illness. However, the value they assign to an intervention that addresses their disease may be biased by self-interest (the same could be said for physicians who specialize in treating that particular condition). Should the public at risk be asked about the utility value that they associate with a given intervention (for example, asking young women to give their preferences regarding breast cancer screening)? Some analysts have expressed doubts regarding the stability, and hence the reliability and the validity, of values expressed by respondents who have not experienced a particular disease state. ${ }^{13}$ Should a representative sector of society decide? The choice of who to ask will determine the utility associated with a given intervention, and it will seldom reflect the values and preferences of a particular patient.

Applying societal values to the care of an individual is problematic. The patient-physician relationship is built on the fundamental premise that the interests of the patient are the major concern of the physician. By focusing on the interests of a group or of society as a whole, economic evaluations fail to incorporate this central premise. In addition, some critics of CEA hold that it fails to take into account important societal ethical beliefs. In particular Menzel identified three major values whose importance to society, as manifested in empirical studies, is neglected by CEA. ${ }^{2}$ The first one is the fact that to promote equality our society strives to treat those who are disadvantaged. Those who are severely ill are given priority with respect to treatment. Second, our society believes that when identifiable patients face a great risk of avoidable death they have a unique claim on resources (rule of rescue) even when this does not lead to societal well being (as opposed to the well being of the individual and his family). The usual example used in this case is the child trapped in a well. Lastly, most people would not choose to withhold treatment from patients who are already burdened with a lower potential for overall health. Thus, people with paraplegia are entitled to the same care as neurologically intact patients even if the expected utility value of their expected clinical health status is lower. Methods have recently been proposed to combine patient and public values into CEA to correct for these biases. ${ }^{2,14}$ Physicians are faced daily with patients to whom these principles apply. The fact that these factors are often not taken into account in CEA should make clinicians wary of generalizing the results of economic evaluations to their encounters with patients.

The perspective of the decision-maker (for example a clinician working with a patient as opposed to a public health physician working with a population) is also important, and it exemplifies the conflict that exists between two different conceptions of health care. On the one hand, a liberal tradition focuses on the protection of individual rights and interests and in the pursuit of the individual good..$^{15}$ This concept goes hand in hand with the perception of the physician 
having an ethical responsibility to act on her patient's best interests regardless of the costs to society. On the other hand, a civic republican tradition based on the idea of community, solidarity, and mutual responsibility is built on the premise that the improvement of societal well being leads to an improvement of the well being of all individuals in society ${ }^{15}$ Under this civic tradition a health care worker would have to consider the interests of society to be equal to, or more important than, those of the individual when determining what course of action to take with any given patient. Some have advocated a framework that puts individual autonomy and social equity into focus simultaneously, as embodied in the concept of citizenship. ${ }^{15}$ However, Danis and Churchill argue that "when there is a conflict between what is best for society and what is best for the patient, the physician should respect self determination and treat according to the patient's wishes, so long as the treatment option is available and expected to yield some benefit."16

Eddy ${ }^{17,18}$ sees an inherent conflict between these two positions as regards health care. For him, a decision-maker working within a public health perspective wants to allocate scarce resources as efficiently as possible across all patients. An individual clinician wants to allocate resources to best serve his patient. The decision-maker and the clinician are both acting towards a similar goal; optimizing the health care provided to those they serve. However, their constituencies are different. The public health physician looks at the problem from the top-down; he is interested in optimizing health for the population as a whole, and would recommend measures that aim to fulfill this need. The expectation is that by implementing measures that optimize the health for the population, all individuals will have better odds of a healthy life. The clinician, on the other hand, looks at the problem from a narrower point of view, that of a particular patient. Eddy maintains that: "The plain fact is that the practitioner's particular role in delivering health care virtually precludes him or her from being able to make resource allocation decisions accurately." ${ }^{\prime 18}$ The reason for this is that a physician faced with an individual patient has to try to give the best odds to that patient. The idea of implementing measures that improve societal well being cannot apply.

\section{Utility of economic evaluations to the clinician}

Methodologically sound economic evaluations of health care can help policy makers allocate resources to those programs that will give the greatest health benefit per dollar to society. CEA is only one element in the decision making process; allocation determinations are influenced by other political and economic considerations.

Physicians can play two roles in the provision of health care, albeit not simultaneously. At the micro level they act as clinicians interacting with particular patients. At this level CEA studies published in the literature are not useful, for the reasons previously discussed. In fact, some authors consider the use of QALYs in clinical decision making dangerous. ${ }^{19}$ When dealing with a patient, clinicians have the fiduciary obligation to act on the patient's best interest, within the constraints set by society. Unilateral rationing by the physician at the bedside has been considered morally unacceptable. ${ }^{20}$ Clinical practice guidelines that maximize cost-effectiveness for individual patients often do not maximize cost-effectiveness for populations of patients, and vice versa. ${ }^{21}$

At the departmental, hospital or governmental level physicians can act as policy makers, and thus have to allocate resources among competing projects. When acting in this capacity, physicians can combine practical clinical expertise with the results of studies that evaluate the economic viability of the various alternatives. They should become familiar with the concepts that underlie such studies, and should be able to evaluate their quality. This use of CEA will lead to evidence-based budgetary limits under which clinicians will practice. The dual role of physicians -as clinicians and as policy makers- justifies the publication of CEA in the clinical literature.

\section{Conclusions}

CEA has limited applicability at the bedside. There are several reasons for this: The clinician cannot make value judgements for society; the perspective used in well designed, technically adequate CEA is not that of the individual patient; the preferences and values used in a CEA may reflect those of society, or the health care system, or the insurance company but not those of someone afflicted by the disease in question; CEA fails to take into account societal values that are relevant to an individual clinical encounter. ${ }^{1,22-24}$ Economic evaluations of health care are designed to help the policy maker allocate resources, not care for individual patients. The physician should use the results of CEA when acting not as a clinician caring for a patient but as a policy maker allocating a budget among competing objectives. 


\section{Acknowledgments}

I would like to thank Jeff Hoch, Ph D, and Julieta Caride, $\mathrm{MBA}$ for their comments during the preparation of the manuscript.

\section{References}

1. W alter SD, Hurley JE, Labelle RJ, Sackett DL. Clinical rounds for nonclinicians: Some impressions. J Clin Epidemiol 1990;43:612-618.

2. Menzel P, Gold MR, N ord E, Pinto-Prades JL, Richardson J, U bel P.Toward a broader view of values in cost-effectiveness analysis of health. Hastings Cent Rep 1999;29(3):7-15.

3. Drummond MF, O 'Brien B, Stoddart GL, Torrance GW. Methods for economic evaluation of health care programmes. ( $2^{\text {nd }}$ ed 0 xford. 0 xford: University Press, 1999.

4. Drummond MF, Jefferson TO, and the BMJ Economic Evaluation W orking Party. Guidelines for authors and peer reviewers of economic submissions to the BMJ. BMJ. 1996;313:275-283.

5. D oubliet $P, W$ einstein $M C, M C N$ eil BJ. Use and misuse of the term "cost effective" in medicine. N Engl J Med 1986;314:253-256.

6. Detsky AS. Terminology I would like to see disappear. Am Heart J 1999;137:S51-S52.

7. Laupacis A, Feeny D, D etsky AS, Tugwell PX. How attractive does a new technology have to be to warrant adoption and utilization? Tentative guidelines for using clinical and economic evaluations. Can Med Assoc J 1992;146:473-481.

8. Gafni A, Birch S. Guidelines for the adoption of new technologies: A prescription for uncontrolled growth in expenditures and how to avoid the problem. Can Med Assoc J 1992;148:913-917.
9. Asch DA. Choices for individual patients vs.groups. N Engl J Med 1990:323:922.

10. Asch DA, Hershey JC.W hy some health policies don't make sense at the bedside. Ann Intern Med 1995;122:846-850

11. G ifford F. 0 utcomes research and practice guidelines: U pstream issues for downstream users. Hastings Cent Rep 1996;26(2):38-44.

12. Redelmeier DA, Tversky A. Discrepancy between medical decisions for individual patients and for groups. N Engl J Med 1990;322:1162-1164. 13. Shiell A, H awe P, Seymour J.Values and preferences are not necessarily the same. Health Econ 1997;6:515-518.

14. U bel PA, Richardson J, Menzel P. Societal value, the person trade-off, and the dilemma of whose values to measure for cost-effectiveness analysis. Health Econ 2000;9:127-136.

15. Jennings $B$. Beyond distributive justice in $H$ ealth Reform. Hastings $C$ ent Rep 1996;26(6):14-16.

16. D anis M, C hurchill LR.Autonomy and the common weal. Hastings $C$ ent Rep 1991;21(1):25-31.

17. Eddy DM. Cost-effectiveness analysis: W ill it be accepted? JAMA 1992;268:132-136.

18. Eddy D M. C ost-effectiveness analysis: A conversation with my father. JAMA 1992;267:1669-1675.

19. LaPuma J, Lawlor E. Q uality adjusted life years: Ethical implications for physicians and policymakers. JAMA 1990;263:2917-2921.

20. Sulmasy DP. Physicians, cost control and ethics. Ann Intern Med 1992;116:920-926.

21. Granata AV, Hillman AL. Competing practice guidelines: Using costeffectiveness analysis to make optimal decisions. Ann Intern Med 1998;128:56-63.

22. D etsky AS, N aglie IG. A clinician's guide to cost effectiveness analysis. Ann Intern Med 1990;113:147-154.

23 Dyer AR. Patients, not costs, come first. Hastings Cent Rep 1986;16(2): 5-6

24. Angell M.The doctor as a double agent. Kennedy Inst Ethics I 1993;3: 279-286. 